\title{
Effect of Dust on the Performance of Solar Water Collectors in Iraq
}

\author{
Omer Khalil Ahmed 1
}

${ }^{1}$ Northern Technical University, Technical institute - Hawija ,Kirkuk, Iraq

\begin{abstract}
In the dusty climate conditions, the dust accumulation on the front surface of solar collectors reduces collector efficiency. There is little research about it in present literatures in Iraq. So the effect of dust accumulation on the performance of conventional of solar collectors is analyzed. The experimental study was carried out mainly on a flat solar collector, which comprised the major part of this work. According to the experimental results obtained, there is a limited decrease in the instantaneous efficiency which was $1.6 \%$ for the dirty collector. At load condition, the outlet temperature reaches a maximum value of $43.85^{\circ} \mathrm{C}$ at 12 noon without dust on the front glass and $33.7^{\circ} \mathrm{C}$ in the presence of the dust. The instantaneous efficiency reaches its maximum value of $49.74 \%$ at 12 noon without dust and $48.94 \%$ with dust after that the efficiency was decreased. The variation of useful transferred energy closely follows the variation of solar intensity and reaches its maximum value of $690 \mathrm{~W} / \mathrm{m}^{2}$ at $12 \mathrm{noon}$ in the presence of the dust for this particular day. It is also observed that, at the second half of the day, there is a large decrease in the instantaneous efficiency resulting from a large reduction in the useful energy transferred. Therefore, for Iraqi places, daily cleaning of the glass covers is strictly recommended as part of the maintenance works but the equipment should be cleaned immediately after a dust storm to keep the collector efficient.
\end{abstract}

Keywords: Dust, Solar collector, Performance, Efficiency, Iraq.

Article History: Received August 16, 2015; Received in revised form Nov 17, 2015; Accepted Dec 19, 2015; Available online How to Cite This Article: Ahmed, O.K (2016). Effect of the Dust on the Performance of Solar Water Collectors in Iraq. Int. Journal of Renewable Energy Development, 5(1), 65-72.

http://dx.doi.org/10.14710/ijred.5.1.65-72

\section{Introduction}

Fossil fuel was the $80 \%$ of our energy consumption in 2013. Since the energy consumption is increasing nowadays, oil reserves, which are not renewable, decrease. According to the United Nation Environment Program (UNEP), oil reserves will last for 52.9 year; natural gas, 55.7 year; and coal reserves, 109 years, taking into account the worldwide energy consumption (Statistical review of world energy 2013).

Solar energy is a natural renewable source which originates in the sun. Solar radiation is a form of energy that be transformed into other types of usable energy: electric energy, thermal energy, etc. The systems that perform this transformation are part of the new clean technologies, which do not harm the environment. Hot water for domestic uses is one of the most common applications of solar energy. The solar water heating system consists of a solar collector and storage tank. The solar collector absorbs the solar energy and transmits it to the circulating water in a form of heat.
Two ways are used to circulate the water in the system, the first is by pump and the other is by natural circulation due to the action of buoyancy force (Duffie, and Beckman 1991).

The performance of solar systems varies as the design variables change, so it is necessary therefore to predict the parameters affecting this design and the operational variables. The problem that facing the world during recent years in the field of the solar energy is settling of atmospheric dust onto the surface of the solar panels (Kasim, Al-Wattar and Abbas 2010; Abd-Elhady, Zayed and Rindt 2011).

In dry and dusty climate conditions, the dust accumulation on the surface of solar collectors reduces much more collector's collection efficiency because the accumulated layer of dust reduces the amount of sunlight reaching the absorber plate which is in turn reduces the amount of warm water produced (Mohammed 2010). The environment in Iraq is similar in the sense that we have a few sand storms annually and almost no rain fall. This leads to the question

${ }^{*}$ Corresponding author: +964-7708080836

Email: omerkalil@yahoo.com

C IJRED - ISSN: 2252-4940, February $15^{\text {th }}$ 2016, All rights reserved 
Citation: Ahmed, O.K (2016). Effect of the Dust on the Performance of Solar Water Collectors in Iraq. Int. Journal of Renewable Energy Development, 5(1),65-72, doi : 10.14710/ijred.5.1.65-72

$\mathrm{P}$ a g e $\mid 66$

whether or not dust is also a problem for solar energy used in Iraq (UNEP, Technical report 2013).

Dust deposition impact on flat plate collectors has been studied by several authors, e.g., ( Hottel and Woertz 1942; Garg 1974; Nimmo and Said 1979; Sayigh, Al-Jandal and Ahmed, 1985; Yahya and Sambo 1991; Ajadi, Fajinmi and Sanusi 2007; Niknia, Yaghoubi and Hessami, 2012; Zhao Jing et.al 2013).

Hottel and Woertz (1942) were amongst the pioneers investigating the effect of dust on solar systems. They recorded a maximum degradation in collector performance of $4.7 \%$, with an average loss in incident solar radiation being less than 1\%. Garg (1974) discovered that dust accumulation on a glass plate tilted at $45^{\circ}$ would reduce the transmittance by an average of $8 \%$ after an exposure period of 10 days. In a work by Sayigh (1985) in Kuwait, it was observed that about 2.5 $\mathrm{g} / \mathrm{m}^{2} /$ day of dust were collected between April and June.

El-Nashar (2009) studied seasonal effect of dust deposition on a field of evacuated tube collectors of a solar desalination plant. Vargas et al. (2009) developed a simplified mathematical model to simulate numerically the transient performance of a solar collector driven water heating and absorption cooling plant system under different operating conditions.

Furthermore, El-Sebaii and Al-Snani (2010) presented the effect of selective coating on thermal performance of flat plate solar air heaters from the view point of radiation heat transfer. The Ministry of Environment, in Iraq recorded 122 dust storms and 283 dusty days, and sources suggest that within the next ten years Iraq could witness 300 dusty days and dust storms per year (Kobler 2013). The solar energy applications in Iraq are facing many problems. One of the most important problems is the accumulation of dust on the solar collector surface which sharply causes the reducing of its performance (Elminir 2006).

The aim of this study is to evaluate the effect of dust deposition on the performance of the solar water heater in Iraq and study the operational parameters that affect the performance of solar water heater. Also, understanding the extent to which dust affects the efficiency of the solar collector because it may help researchers understand ways to prevent hindrance. This study could provide important information for future studies that would look to maximize solar energy effectiveness and prevent the negative effects of dust on solar collector efficiency.

\section{Experimental approach}

The equipment Mini-EESTC developed by EDIBON as shown in Fig.1 is a system built to transform solar energy into thermal energy. This device uses the thermosiphon solar system to heat water, or the traditional pumping system. In both cases, the thermal energy absorbed is given by the simulated solar radiation; in this case, it is done by using a panel with strong light sources.

The experimental rig consists of the following elements: thermal solar panel, tank, solar simulator, lamp, pump, temperature sensors, flow sensor, and valves to work in the thermosiphon mode or pumping mode. The solar panel is made of polycarbonate. It is mounted on an aluminium structure with a copper conduct for the thermal fluid. It has been developed carefully taking into account the geometrical shape of the absorbing surface in order to obtain the highest output levels possible. The solar collector is mounted on an aluminium frame and the fluid (water) flows through cooper tubes. It has been developed in such a way that the geometrical shape of the surface allows the most efficient absorption. The accumulator tank is protected with an anti-corrosive material. The tank satisfies the set standards both in its construction and in its equipment. The hot water outlet passes through an overflow placed at the top of the tank. Its capacity is 30 litres.

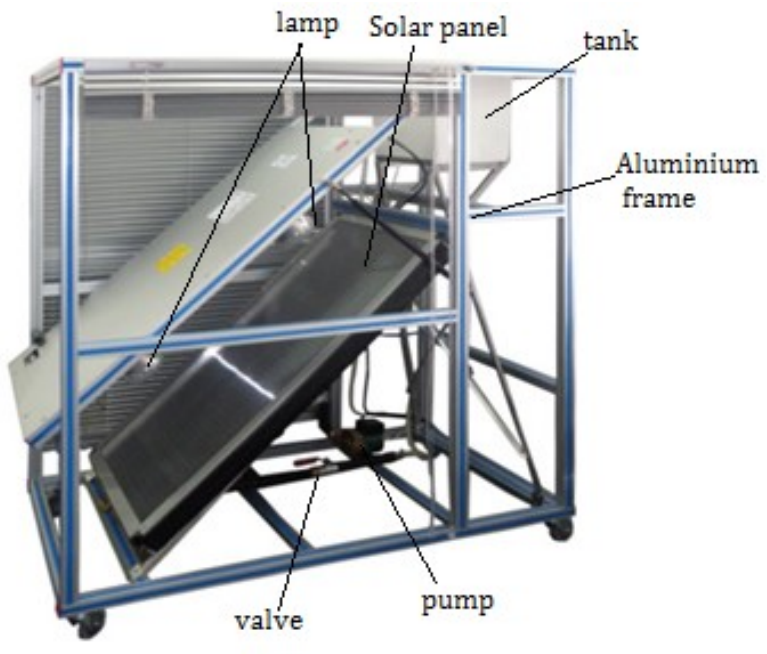

Figure 1 Experimental rig which used in the study

The lamps present radiation features that are similar to the sun radiation, which is measured by a radiation sensor. The light is converted into heat in the solar collector and transferred to the heat transfer fluid. Three different configurations can be simulated with the solar simulator: all the lamps are turned on, half of the lamps are turned on in zig-zag, or only one lamp is turned on.

This unit makes it possible to simulate two different functioning modes: thermosiphon mode, the water is moved due to the temperature differences, that is to say, without pump, and pumping mode. The five temperature thermocouples type (J) ST-1, ST-2, ST-3, ST-4, and ST-5 as shown in Fig. 2 allow knowing the temperature at different points of the device. The flow meter and the flow sensor allow knowing the water that is running through the pump and the collector. 


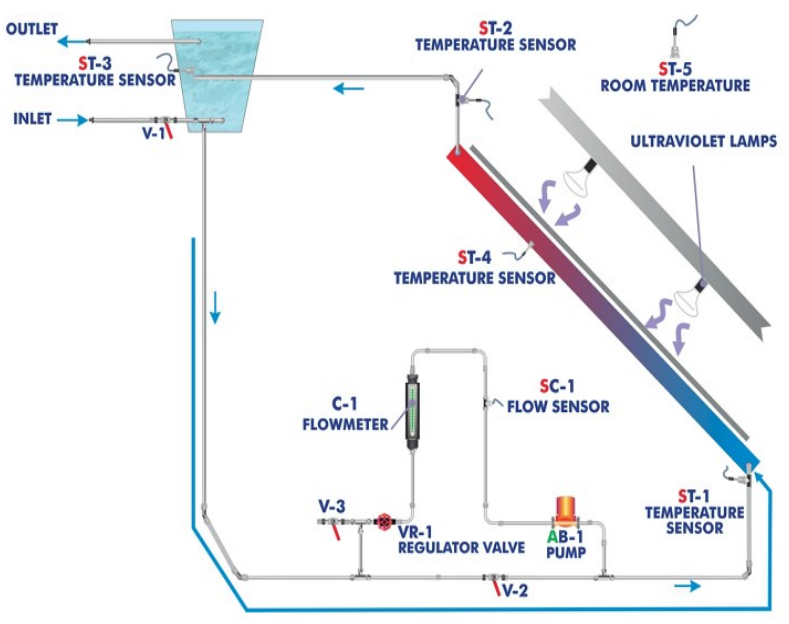

Figure 2 The location of different sensor in the experimental rig

In the present work, the system in Fig.1 was used to study the effect of dust that accumulated on the solar panel surface which leads to decrease the transmission of solar radiation to the solar collector to decrease its performance.

Two cases was achieved to evaluate the effect of the dust: the first case where the front glass cover was cleaned to a high degree, while in the second case, the specific amount of the dust is sprayed on the front surface for evidence the effect of dust. Dust is defined as the minute solid particles less than $500 \mu \mathrm{m}$ in diameter. Dust deposition is a function of various environmental and weather conditions (Mani \& Pillai 2010). In this project, natural dust was used to represent the dust accumulation. $0.025 \mathrm{gram} / \mathrm{cm}^{2}$ of dust is sprayed on the front face of collector.

The collectors were tested under steady-state conditions in which the solar intensity, wind speed, and the ambient temperature were considered constant for a period of time. At the onset of each experiment the collector was filled with fresh water, the thermal sensors were checked. The measuring instruments were switched on. The data recorded at the end of each test included the various temperatures storage, glass cover, absorber plate and the tank inlet and outlet as well as the flow rate of the withdrawn hot water during the test run for each load pattern. The test run was repeated with and without for each load pattern. Some experiments were carried out with a load condition. The load was connected to the collector in such a way that the cold inlet water entered at the bottom of collector and the hot water outlet was taken from the top of storage tank. The mass flow rate of load water was regulated by a valve at the inlet of the collector. The load mass flow rate was calibrated by timing the water collected in a graduated vessel of 1 litres capacity. The temperature of the inlet and outlet of the load water were recorded at the same time as the other data.

Mainly, the energy input in solar collector is in form of solar radiation from the sun and the thermal fluid flowing inside the copper tube from inlet. The energy out from the system is due to heat loss by convection and thermal fluid outflow from the collector. The total energy gain is expressed as (Hussain and Leem 2014):

$q_{u}=A_{c} F_{R}\left\lfloor S-U_{\text {loss }}\left(T_{f . i n}-T_{a}\right\rfloor\right.$

Where: $q_{u}$ is the total energy gain (W), $A_{c}$ is collector area $\left(\mathrm{m}^{2}\right), S$ is absorbed solar energy $\left(\mathrm{W} / \mathrm{m}^{2}\right)$.

$S=I_{c} \tau_{S} \alpha_{S}$

Where $I_{c}$ is solar irradiance $\left(\mathrm{W} / \mathrm{m}^{2}\right)$, $\tau_{s} \& \alpha_{s}$ Transmittivity and absorbtivity of the glass cover (Al-azzawi 2014).

In a rainless 30-day experiments experiment in India, It is found that dust reduced the transmittance by an average of $8 \%$ for glass tilted at $45^{\circ}$ (Garg, 1974).

To show the effect of the dust in the Iraqi climate, it is suggested that radiation absorbed by the plate be reduced by $2 \%$ (Mastekbayeva and Kumar 2000).

$U_{\text {loss }}$ is heat loss factor $\left(\mathrm{W} / \mathrm{m} .{ }^{\circ} \mathrm{C}\right)$ and calculated from the following equation (Klein 1975):

$$
\begin{aligned}
& U_{\text {loss }}=\left[\frac{N}{\left(\frac{C}{T_{p m}}\right)\left[\frac{T_{p m}-T_{a}}{N+f}\right]^{e}+\frac{1}{h_{w}}}\right]^{-1}+ \\
& \frac{\sigma\left(T_{p m}+T_{a}\right)\left(T_{p m}^{2}+T_{a}^{2}\right)}{\frac{1}{\varepsilon_{p}+0.005 N h_{w}}+\frac{2 N+f-1+0.133 \varepsilon_{p}}{\varepsilon_{g}}-N}
\end{aligned}
$$

$N=$ Number of glass covers

$f=\left(1+0.089 h_{w}-0.1166 h_{w} \varepsilon_{p}\right)(1+0.07866 N)$

$C=520\left(1-0.000051 \beta^{2}\right)$.

$\beta$ is the collector tilt (degree), $\varepsilon_{p}$ and $\varepsilon_{\mathrm{g}}$ are the emittance of plate and glass respectively.

$e=0.43\left(1-100 / T_{p m}\right)$

$T_{p m}$ is the mean plate temperature $\left({ }^{\circ} \mathrm{C}\right), h_{w}$ is wind heat transfer coefficient and calculated from (Gowda et al 2014):

$h_{w}=5.7+3.8 \cdot V_{\infty}\left(V_{\infty}\right.$ is wind velocity $\left.(\mathrm{m} / \mathrm{s})\right)$.

$\mathrm{F}_{\mathrm{R}}$ is called the collector heat removal factor. In equation form it is (Saad and Mohamaad 2011): 
Citation: Ahmed, O.K (2016). Effect of the Dust on the Performance of Solar Water Collectors in Iraq. Int. Journal of Renewable Energy Development, 5(1),65-72, doi : 10.14710/ijred.5.1.65-72

P a g e $\mid 68$

$F_{R}=\frac{\dot{m} c_{p}}{A_{c} U_{\text {loss }}}\left[1-\exp \left(-\frac{U_{\text {loss }} A_{c} F^{\prime}}{\dot{m} c_{p}}\right)\right]$

$\dot{m}$ is the mass flow rate $(\mathrm{kg} / \mathrm{s}), c_{p}$ is specific heat of water $=\left(4180 \mathrm{~kJ} / \mathrm{kg} \cdot{ }^{\circ} \mathrm{C}\right)$

$F^{\prime}$ is called as the collector efficiency factor and calculated from :

$$
F^{\prime}=\frac{1 / U_{\text {loss }}}{(D+2 w)\left[\frac{1}{U_{\text {loss }}\left(D+2 w \eta_{f}\right)}+\frac{1}{C_{p}}+\frac{1}{\bar{h}_{c, i}\left(\pi D_{i}\right)}\right]}
$$

The term $\eta_{f}$ is standard fin efficiency and calculated from:

$$
\begin{aligned}
& \eta_{f} \equiv \frac{\tanh m w}{m w} \\
& m=\frac{U_{\text {loss }}}{k t}
\end{aligned}
$$

Where $t$ the thickness of the absorber plate $(\mathrm{m}), k$ Thermal conductivity of the absorber plate $\left(\mathrm{W} / \mathrm{m} .{ }^{\circ} \mathrm{C}\right), T_{\text {fin }}$ is the Inlet water temperature $\left({ }^{\circ} \mathrm{C}\right), T_{a}$ is the ambient air temperature $\left({ }^{\circ} \mathrm{C}\right), \mathrm{D}$ is the diameter of collector tubes $(\mathrm{m}), w$ is distance between two tubes $(\mathrm{m}), \bar{h}_{c, i}$ is heat transfer coefficient inside the tube $\left(\mathrm{W} / \mathrm{m}^{2}{ }^{\circ} \mathrm{C}\right)$

The mean plate temperature can be used to calculate the useful gain of a collector, and calculated from the following equation (Kalogirou 2004):

$$
T_{p m}=T_{f, i n}+\frac{q_{u} / A_{c}}{F_{R} U_{l o s s}}\left(1-F_{R}\right)
$$

The mean fluid temperature was shown by the following relation:

$$
T_{f m}=T_{f i}+\frac{q_{u} / A_{c}}{F_{R} U_{l o s s}}\left(1-\frac{F_{R}}{F^{\prime}}\right)
$$

The instantaneous efficiency of the collector can be found from the following relation:

$\eta_{c}=F_{R} \alpha_{s} \tau_{s}-\frac{\left\lfloor F_{R} U_{\text {loss }}\left(T_{f . i n}-T_{a}\right)\right\rfloor}{I_{c}}$

Solar collector efficiency is plotted as a straight line against the parameter $\left(\mathrm{T}_{\text {fin }}-\mathrm{T}_{\mathrm{a}}\right) / \mathrm{I}_{\mathrm{c}}$, where $\mathrm{T}_{\text {fin }}$ is the collector inlet temperature, $\mathrm{T}_{\mathrm{a}}$ is the ambient air temperature, and $I_{c}$ is the intensity of the solar radiation. The plots of collector efficiency $\left(\eta_{c}\right)$, versus
$\left(T_{f i n}-T_{a}\right) / I_{c}$ would be straight lines with intercept $F R(\tau \alpha) n$ and slope $-F_{R} U_{\text {c }}$.

A computer program using FORTRAN language was built to calculate the various parameters by using the previous equations in the section.

\section{Results and discussions}

The experiments were carried out at the technical institute of Hawija city in Iraq located at $\left(35.33^{\circ} \mathrm{N}, 43.77\right.$ $\left.{ }^{\circ} \mathrm{E}\right)$. Typical results are presented. This article presents the results of a study done to assess the influence of dust on the performance of solar collector under arid climatic conditions.

\subsection{Solar absorbed energy}

Figure 3 shows the variation of the solar radiation intensity, absorbed solar energy transferred per unit absorber area without dust and the absorbed solar energy in the present of dust on the glass cover of solar collector during a typical winter day. The solar intensity was calculated by using the solar intensity meter which presented in the experimental approach. The absorbed solar energy was calculated from equation 3, the variation of useful transferred energy follows closely the variation of solar intensity and reaches its maximum value of $755 \mathrm{~W} / \mathrm{m}^{2}$ at 12 noon without dust on the front glass of collector, while the maximum value was only $625 \mathrm{~W} / \mathrm{m}^{2}$ at 12 noon for the collector with dust on the front glass of collector.

\subsection{Mean plate and fluid temperatures}

The hot water withdrawn was taking continuously. This was done by permitting cold mains water to enter the collector at its bottom, and the hot water was withdrawn from the top of the collector. The mass flow rate and temperature of the water were both measured. Figure 4 and 5 show the variation of system temperatures for a clear summer day with continuous load condition. The mass flow rate was $0.015 \mathrm{~kg} / \mathrm{s}$ where the total hot water removed during the whole working period was $700 \mathrm{~kg}$ or 700 liters.

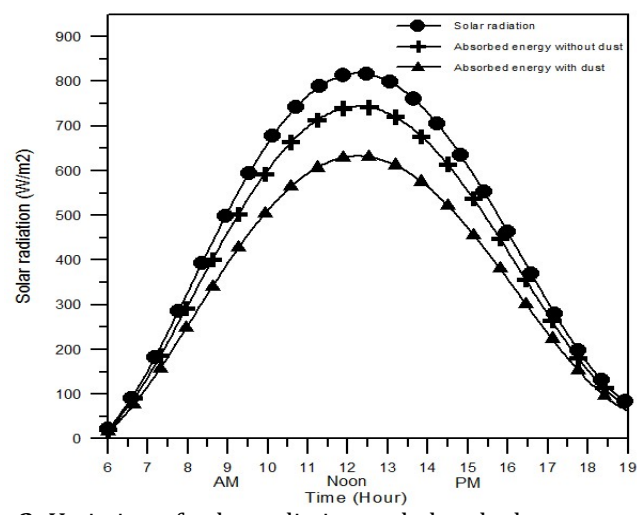

Figure 3. Variation of solar radiation and absorbed energy with and without dust. 
Fig. 4 shows the variation of mean plate temperature during a typical clear summer day. It is observed that the mean storage temperature increased with time until the midday, the mean storage temperature reaches its maximum value and then decreases after midday. This is because the net energy absorbed becomes just lower than the useful energy which transferred to the water and heat losses. The maximum value of mean plate temperature was $39.22^{\circ} \mathrm{C}$ for this particular day without dust on the glass while with dust, the maximum value of mean plate temperature was $37.4^{\circ} \mathrm{C}$. This trend is typical of solar water heating systems (Saad and Mohamaad 2011; Khatik et. al. 2014).

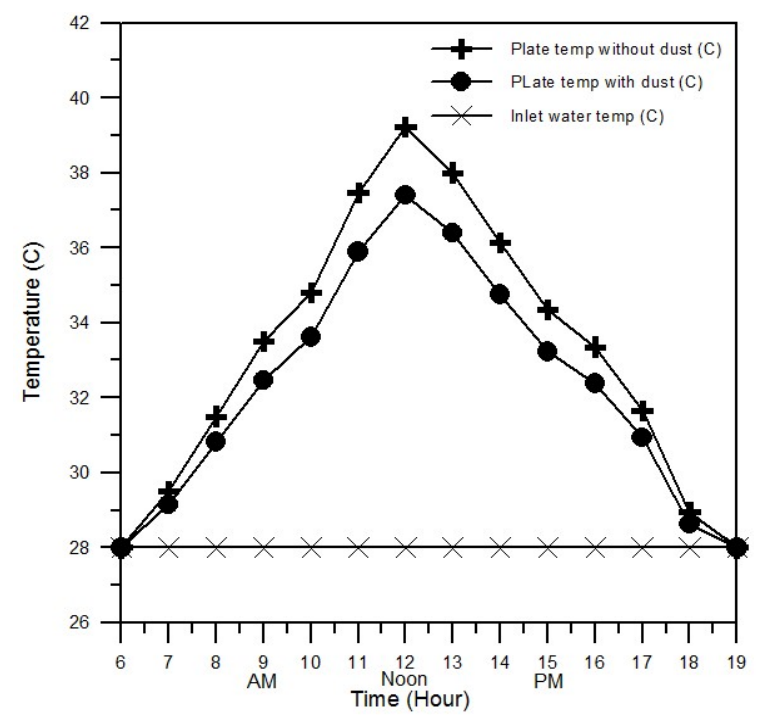

Figure 4 Variation of Mean plate temperature with and without dust at $0.015 \mathrm{~kg} / \mathrm{s}$ flow rate.

The agreement between the numerical predictions was calculated by Eq. 7 and the experimental data is good as shown in Figure 5. As shown in Fig. 6, the variation of mean fluid temperature during a typical clear summer day. It is observed that the mean fluid temperature increased with time until the midday and then decreased, which means that the useful energy transferred to the water is insufficient to cause any further increase in the mean fluid temperature.

This behavior is usual and similar to other researcher (Saleh 2012). The maximum value of mean fluid temperature was $34.8{ }^{\circ} \mathrm{C}$ for this particular day without dust on the glass while with dust, the maximum value of mean fluid temperature was $33.7^{\circ} \mathrm{C}$.

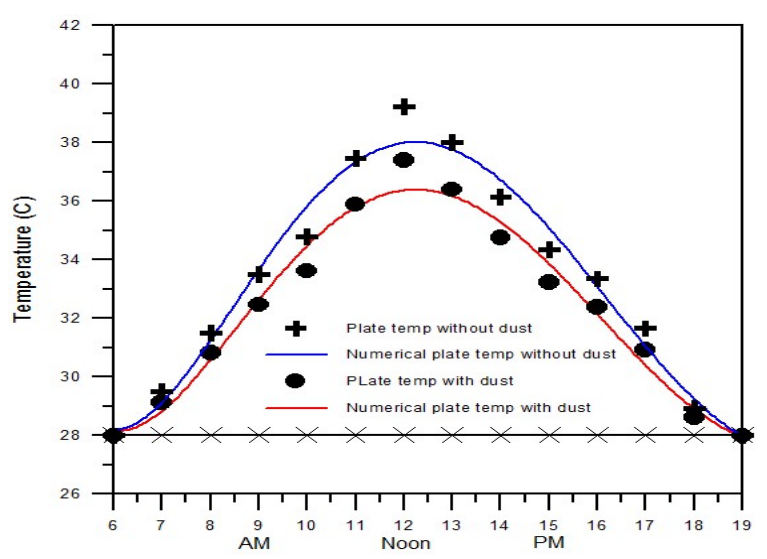

Figure 5 Comparison between numerical and experimental data of mean plate temperature with and without dust.

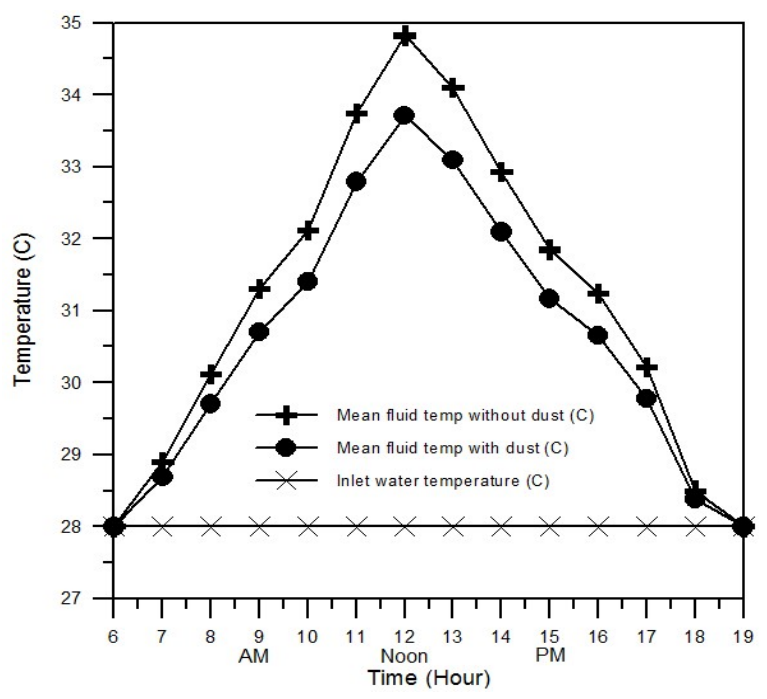

Figure 6 Variation of Mean fluid temperature with and without dust at $0.015 \mathrm{~kg} / \mathrm{s}$ mass flow rate.

\subsection{Loading effect}

In order to show the effect of loading conditions on the solar water heater performance, some experiments were carried out with hot water withdrawal from the collector. The hot water withdrawn was taking continuously. This was done by permitting cold mains water to enter the collector at its bottom, and the hot water was withdrawn from the top of the collector. The mass flow rate and temperature of the water were both measured. Figure 7 shows the effect of loading on the variation of mean fluid temperature during a typical day. It is observed that the mean fluid temperatures are increasing throughout the period between 6 a.m. and 12 noon, which indicates that the useful energy $\left(\mathrm{q}_{\mathrm{u}}\right)$ is higher than that carried out by the load water. After midday, these temperatures start decreasing because the value of useful energy becomes lower than the energy carried out by the load water. 
Citation: Ahmed, O.K (2016). Effect of the Dust on the Performance of Solar Water Collectors in Iraq. Int. Journal of Renewable Energy Development, 5(1),65-72, doi : 10.14710/ijred.5.1.65-72

$\mathrm{P}$ a g e $\mid 70$

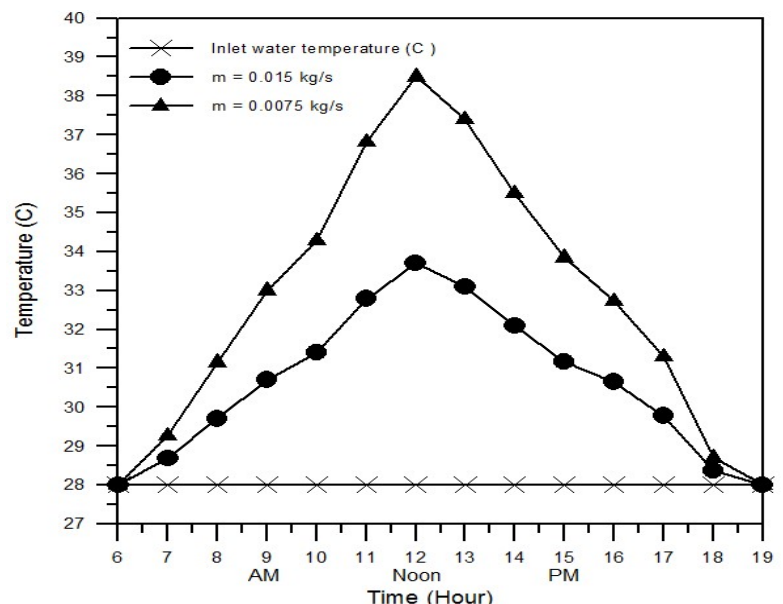

Figure 7 Variation of Mean fluid temperature with different mass flow rate with dust.

Reduction of mass flow rate leads to increase the mean fluid temperature because reduction in the energy that transferred with the outlet water as shown in Fig. 7. The mean fluid temperature reaches the maximum value of $38.55{ }^{\circ} \mathrm{C}$ when the mass flow rate was $0.0075 \mathrm{~kg} / \mathrm{s}$ while the maximum mean fluid temperature was $33.7{ }^{\circ} \mathrm{C}$ at $0.015 \mathrm{~kg} / \mathrm{s}$ mass flow rate, which indicates that the useful energy that carried out by the load water at $0.015 \mathrm{~kg} / \mathrm{s}$ higher than other case $(0.0075 \mathrm{~kg} / \mathrm{s})$. Therefore, the outlet water temperature for this case becomes lower than the outlet water temperature at $0.0075 \mathrm{~kg} / \mathrm{s}$.

Presence of dust causes decreasing in the rates of mean temperatures as shown in Figure 8. The maximum mean temperature was $40.55^{\circ} \mathrm{C}$ without dust while this value was $38.55^{\circ} \mathrm{C}$ in the presence of the dust on the front glass of solar collector.

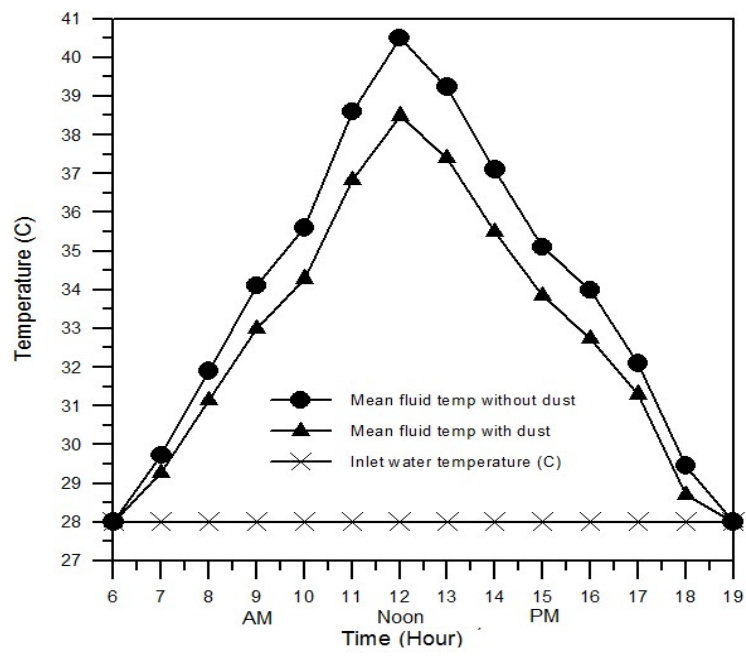

Figure 8 Variation of Mean fluid temperature with and without dust when the mass flow rate equal to $0.0075 \mathrm{~kg} / \mathrm{s}$

\subsection{Instantaneous efficiency}

Figs. 9 and 10 show the variation of the instantaneous collector efficiency and the useful energy transferred per unit absorber area during a typical day at load conditions. The useful transferred energy was calculated from Equation 1, and the instantaneous efficiency of the collector was calculated from Equation 9. Figure 9 shows there are high increase in the instantaneous efficiency during the first hours of the operating period 8-10 a.m. This is because the large increase in the net energy absorbed, coupled with relatively small heat losses from the collector to the ambient atmosphere. Also, the instantaneous efficiency reaches its maximum value of $49.74 \%$ at 12 noon without dust and $48.94 \%$ with dust after that the efficiency was decreased.

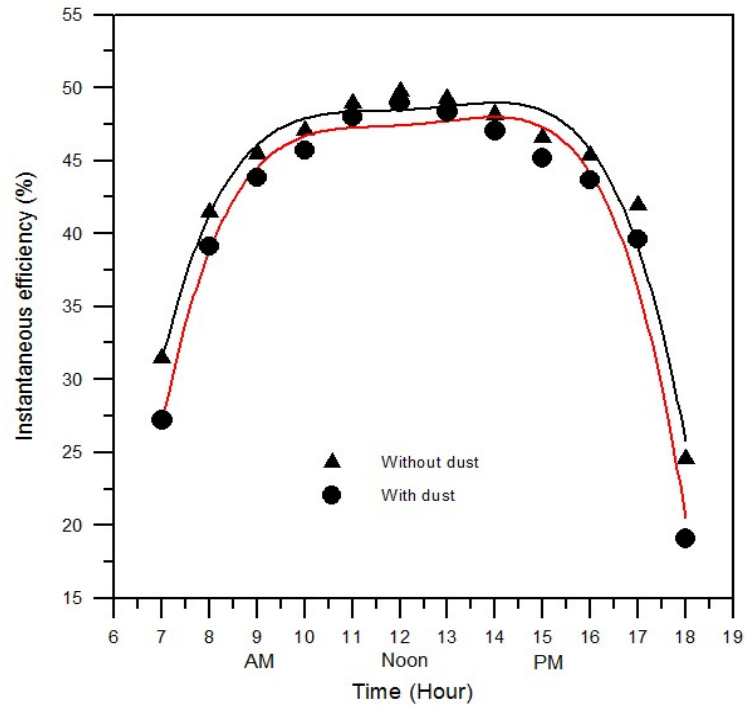

Figure 9 Variation of Instantaneous efficiency with and without dust when the mass flow rate equal to $(0.015 \mathrm{~kg} / \mathrm{s})$

This trend is due to increasing heat losses during the day, accompanied with decreasing net energy absorbed in the afternoon hours. It is also observed that, at the second half of the day, there is a large decrease in the instantaneous efficiency resulting from a large reduction in the useful energy transferred. The variation of useful transferred energy closely follows the variation of solar intensity and reaches its maximum value of $690 \mathrm{~W} / \mathrm{m}^{2}$ at 12 noon in the presence of the dust for this particular day. The maximum value was only $825 \mathrm{~W} / \mathrm{m}^{2}$ at 12 noon for a typical day as observed from Figure 10. This trend is typical of solar water heating systems (Saad and Mohamaad 2011, Garg 1974). 


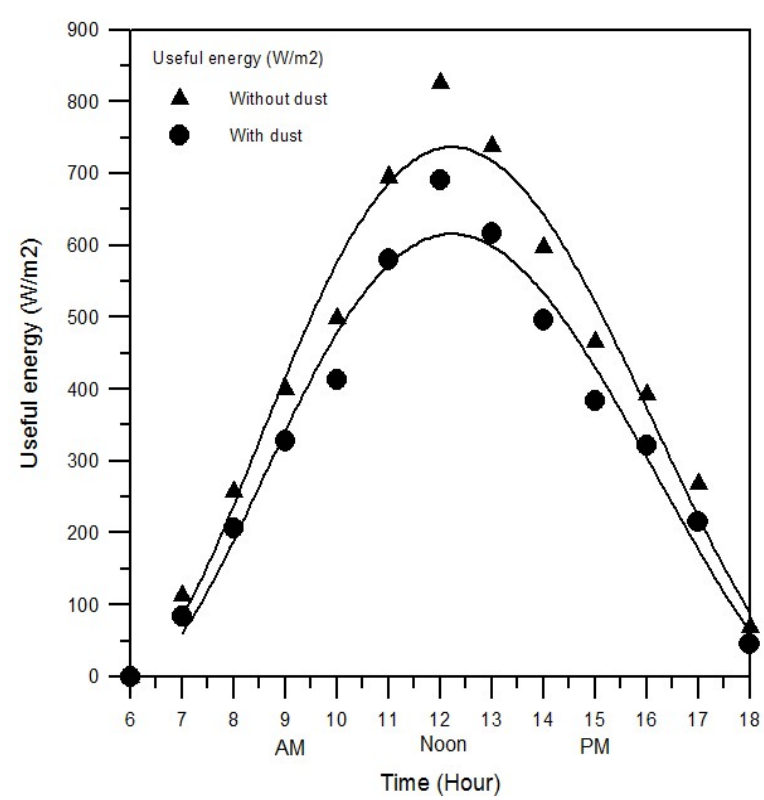

Figure 10 Variation of Useful energy with and without dust when the mass flow rate equal to $0.015 \mathrm{~kg} / \mathrm{s}$

Figure 11 shows the effect of the dust on the relation between the relation between efficiency and the $\left(\mathrm{T}_{\text {fin- }}\right.$ $\mathrm{T}_{\mathrm{a}}$ )/ $\mathrm{I}_{\mathrm{a}}$ (Hottel and Woertz 1942). The intersection of the line with the vertical axis is where the temperature of the fluid entering the collector equals the ambient temperature, and collector efficiency is at its maximum. At the intersection of the line with the horizontal axis, collector efficiency is zero. From the result of the previous section, the equation of this curve as below:

1. Without dust:

$\eta_{c}=0.5035-2.338 \frac{\left\lfloor\left(T_{f . i n}-T_{a}\right)\right\rfloor}{I_{c}}$

2. With dust:

$\eta_{c}=0.5518-5.34 \frac{\left\lfloor\left(T_{f . i n}-T_{a}\right)\right\rfloor}{I_{c}}$

In comparison equations 10 and 11 with equation 9, we find that $F_{R} \cdot U_{\text {loss }}=2.338$ for clear collector and $F_{R} \cdot U_{\text {loss }}=5.34$ for dusty collector, the value of heat removal factor $F_{R}$ can be calculated from Eq. 4 and equal to 0.705 , that mean the heat transfer losses coefficient $U_{\text {loss }}$ equal to $3.316 \mathrm{~W} / \mathrm{m}^{2} . \mathrm{K}$ for clear collector and equal to $7.5744 \mathrm{~W} / \mathrm{m}^{2} . \mathrm{K}$ for dusty collector, this value is high and to enhancement the performance the collector, reduction of this value is very necessary. The efficiency of the collector in clear day is greater than the collector in the dusty day. Notice the collector efficiency at the dusty day drops off very quickly as temperature increases because the reducing of the solar radiation that reached the absorbed plate.

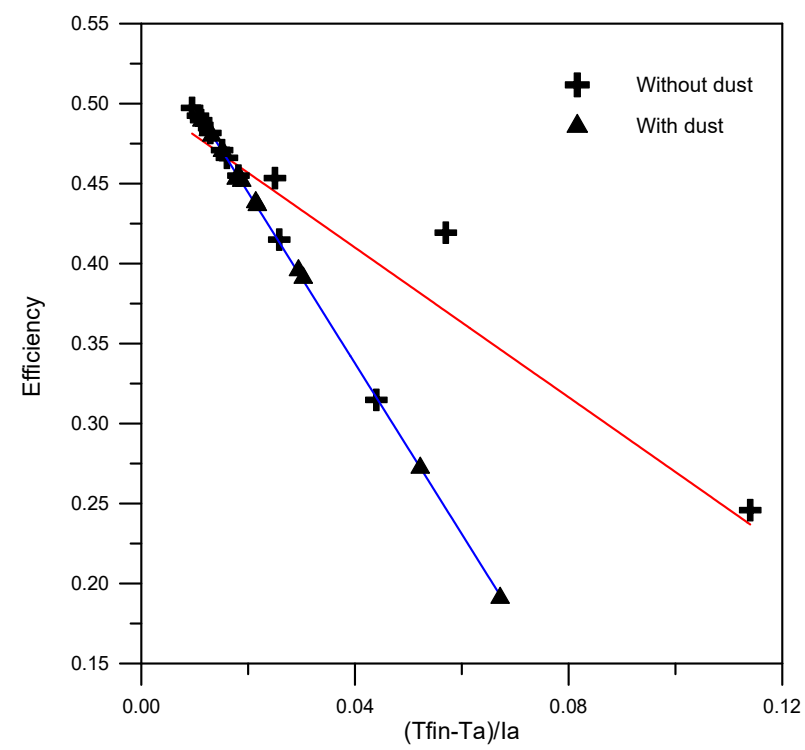

Figure 11 The relation between efficiency and the $\left(T_{f i n}-T_{a}\right) / I_{a}$

\section{Conclusions}

From the results presented, the many main conclusions can be obtained. Deposition of airborne dust on front glass of solar collector may decreases the transmittance of solar glazing and causes a significant degradation of absorbed solar energy by certain percentage, according to the impact of the amount of dust. There is a significant decrease in the instantaneous efficiency which was $1.6 \%$ for the dirty collector.

At load condition, the outlet temperature reaches maximum value of $43.85^{\circ} \mathrm{C}$ at 12 noon without dust on the front glass and $33.7^{\circ} \mathrm{C}$ in the presence of the dust. Also it showed from the behaviour of performance parameters in the solar collector in the presence of the dust is similar to solar water heaters without dust.The result of this paper lead to using appropriate cleaning schedule depends on water availability for Iraqi environment.

\section{References}

Abd-Elhady, M.S., Zayed, S.I. and Rindt, C.C.. (2011) Removal of dust particles from the surface of solar cells and solar collectors using surfactants, Proceedings of international conferences on heat exchanger fouling and cleaning, June, Crete Island, Greece. 342348.

Ajadi, D.A, Fajinmi, G.R. and Sanusi,Y.K. (2007) Effect of dust on the performance of a locally designed solar dryer, Research journal of applied sciences,2(3), 251-254.

Al-azzawi, S.M.. (2014) Effect of dust on transmittivity of glass, International Journal of Application or Innovation in Engineering \& Management (IJAIEM), 3(2), 8-11.

British Petroleum Company. (2013) Bp Statistical review of world energy. www.bp.com.

Duffie, J.A., Beckman, W.A. (1991) Solar Engineering of Thermal Process, John Wiley and sons, New York. 
Elminir, H. K., (2006) Effect of dust on the transparent cover of solar collectors, Energy Conversion and Management, 47(18), 31923203.

El-Nasharm A.M. (2009) Seasonal effect of dust deposition on a field of evacuated tube collectors on the performance of a solar desalination plant, Desalination, 239, 66-81.

El-Sebaii, A. A., Al-Snani, H. (2010) Effect of selective coating on thermal performance of flat plate solar air heaters. ENERGY, 35 1820-1828.

Garg, H.P. (1974) Effect of dirt on transparent covers in flat plate solar energy collectors. Solar Energy, 15(4), 299-302.

Gowda, N., Gowda, B. B. and Chandrashekar, R. (2014) Investigation of mathematical modelling to assess the performance of solar flat plate collector, International journal of renewable energy research, 4(2), 255-260.

Hottel H, Woertz M. (1942) Performance of flat plate solar heat collectors, Trans American society of mechanical engineering, 64, 94-102.

Hussain, M.I., Leem, G.H. (2014) Numerical and experimental analyses of solar energy collector for concentrating photovoltaic co-generation System, International Conference of Agricultural Engineering, Zurich, 1-7.

Kalogirou, S.A, (2004) Solar thermal collectors and applications, Progress in Energy and Combustion Science, 30(3), 231-295.

Kasim N.K., Al-Wattar, A.J. and Abbas, K.K. (2010) New Technique for Treatment of the dust accumulation from PV solar panels surface, Iraqi Journal of Physics, 8(12), 54-59.

Khatik, J.S., Yeole, S.V. and Juned, A. R. (2014) Comparative experimental study of simple absorber plate with absorber plate having concavities, International journal of research in engineering and technology, 3(8), 13-15.

Klein, S. A., (1975) Calculation of Flat-Plate Loss Coefficient, Solar Energy, 17, 79-80.

Kobler, M. (2013) Dust storms of Iraq, UN Secretary General for Iraq, A ministerial meeting in Nairobi, Kenya.

Mani, M., Pillai R., (2010) Impact of dust on solar photovoltaic (PV) performance: research status, challenges and recommendations. Renewable and Sustainable Energy Reviews, 14(9), 3124-3131.

Mastekbayeva, G.A., Kumar, S. (2000) Effect of dust on the transmittance of low density polyethylene glazing in tropical climate, Solar Energy, 68(2), 135-141.
Mohammed, B.A. (2010) Correlation between solar cycles and dust activity over Iraq .Journal of Al-Nuhrain university, 13(3), 82-87.

Niknia, I, Yaghoubi, M and Hessami, R. (2012) A novel experimental method to find dust deposition effect on the performance of parabolic trough solar collectors, International Journal of Environmental Studies, 69(2), 1-20.

Nimmo B , Said SAM. (1979) Effects of dust on the performance of thermal and photovoltaic flat plate collectors in Saudi Arabiapreliminary results, Proceedings of the 2nd Miami International Conference on Alternative Energy Sources,1, 145-152.

Saad T.H, Mohamaad A. F. (2011) Prediction of thermal characteristics for solar water heater, Anbar journal for engineering sciences, $4(2), 18-32$.

Saleh, A.M., (2012) Modelling of flat-plate solar collector operation in transient states, Master thesis, Purdue university.

Sayigh, A.A.M, Al-Jandal, S. and Ahmed, H.,1985 Dust effect on solar flat surface devices in Kuwait, Workshop in physics of nonconventional energy sources and material science for energy, Triest, Italy, 353-367.

UNEP (Technical report), (2013) Establishing a WMO Sand and Dust Storm Warning Advisory and Assessment System Regional Node for West Asia: Current Capabilities and Needs, World Meteorological Organization, Geneva, Switzerland.

Vargas, J.V, Ordonez, J.C., Diley, E. and Parise, J.A. (2009) Modelling, simulation and optimization of a solar collector driven water heating and absorption cooling plant. Solar Energy, 83, 12321244 .

Yahya, H.N, A.S. Sambo, (1991) The effect of dust on the performance of photovoltaic modulus in Sokoto, Nigeria, Nigerian journal of renewable energy, 36-42.

Zhao, J. , Wang , Z., Wang K. and Liu J. (2014), Dust effect on thermal performance of flat plate solar collectors, Journal of Solar energy Engineering, 137(1), 1-5. 